Research Article

\title{
Optimized Partition Scheme for Prefabricated Underpass with Large Cross Section
}

\author{
Zhiyi Jin $\mathbb{D}^{1,2}$ Taiyue Qi ${ }^{1,}{ }^{1,2}$ Xiao Liang, ${ }^{1,2}$ and Bo Lei $\mathbb{D}^{1,2}$ \\ ${ }^{1}$ Key Laboratory of Transportation Tunnel Engineering, Ministry of Education, Southwest Jiaotong University, \\ Chengdu 610031, China \\ ${ }^{2}$ School of Civil Engineering, Southwest Jiaotong University, Chengdu 610031, China \\ Correspondence should be addressed to Taiyue Qi; qitaiyue85@126.com
}

Received 15 September 2020; Revised 26 March 2021; Accepted 7 April 2021; Published 23 April 2021

Academic Editor: Guoyang Fu

Copyright (c) 2021 Zhiyi Jin et al. This is an open access article distributed under the Creative Commons Attribution License, which permits unrestricted use, distribution, and reproduction in any medium, provided the original work is properly cited.

\begin{abstract}
With the acceleration of urbanization in China, more underpasses will be constructed in big cities to alleviate the great traffic pressure. The prefabricated and assembly construction method has been introduced to replace the traditional cast-in-place method to achieve quick construction. However, for a fully prefabricated and assembled underground structure (PAUS) with large cross section, the structure must be cut into segments in transverse direction to reduce the size and weight for easy transportation and assembly. Therefore, how to develop an optimal partition scheme is a new problem to be studied. Firstly, three preliminary partition schemes were proposed based on the internal force distribution and completed engineering practices. Then, the three schemes were compared in terms of bending moment, shear force, and axial force. The construction efficiencies were also compared with special emphasis on difference of the build period. Finally, an optimal partition scheme was determined and successfully applied in the real project. Furthermore, the construction period of this partition scheme was $1 / 3$ of the traditional cast-in-place method. The results of the current paper can provide some design guidance to large cross-sectional underpasses and other underground structures in the partition stage.
\end{abstract}

\section{Introduction}

With the fast development of urbanization in China, traffic congestion has become an urgent problem in big cities. To relieve the traffic pressure, many underpasses have been constructed in these areas. However, the construction of most underpasses is based mainly on traditional cast-inplace concrete technology, which has both adverse environmental and social adverse effects, such as long construction time, large construction space, and environmental pollution. Thus, due to the improvements in building technology, the increasing public awareness of the importance of protecting the environment, and the need for construction to take place quickly, the national and local governments have issued policies that vigorously promote the use of prefabricated buildings. Therefore, in the coming decades, the traditional cast-in-place structures will be replaced by prefabricated assembly structures (PAS). Van
Casteren studied the feasibility of placing PAUs under the railway, and it was concluded that PAUs were both technically and economically feasible [1].

Prefabricated and assembly technology has a long history in the construction of underground structures, and it has been used in many practical projects in some developed countries, such as Japan, Tashkent subway Soviet Union, Netherlands, and France [2-6]. In recent years, with the advancements of both machinery and building technology, several PAUs have been built successfully in China, for example, the Shugang road municipal underpass beneath Xianyue road and a prefabricated utility tunnel [7].

When the method used to construct underpass changed from the traditional cast-in-place method to the use and assembly of prefabricated components, it was inevitable that new problems would arise. These problems include (1) determining how to cut underpasses with large cross sections into segments, (2) determining where to locate the 
joints, and (3) and determining the behaviors of joints under different loads. Shield tunnels are the most widely and extensively used type of fabricated and assembly tunnels.

For circular shield tunnels, the partition scheme is often determined by the external diameter of the tunnel. The external diameter of most metro shield tunnels is around $6.5 \mathrm{~m}$, and the number of segments is $6(3+2+1)$, which includes 3 standard segments, 2 adjacent segments, and 1 key segment. There are two main reasons for 4 or 5 segments schemes: one is that it is difficult to design hand holes and the other is that the key segment must be assembled in the radial direction [8]. For shield tunnels with diameter around $11 \mathrm{~m}$, the number of segments is generally 8 to 10 . Based on the project of Wuhan crossing Yangtze River shield project, Lu studied 5 partition schemes of the external diameter of $11.38 \mathrm{~m}$ shield lining in terms of internal force and deformation of the lining structure and decided the ultimate partition scheme as the 9 segments, with every segment having an arc center angle of $40^{\circ}$ [9]. Yan et al. studied the structural parameters of shield tunnel lining with large cross section using statistical methods and found that there was a positive correlation between the number of segments and the diameter of shield tunnel [10]. Based on a double-shield TBM highway tunnel with an excavation diameter of $9.3 \mathrm{~m}$, two partition schemes of the segments were compared by numerical simulation; the results showed that the mechanical properties of the segment structure in the " $X+1$ " mode are better than those of the one in the "equal parts" mode, and the " $6+1$ " scheme was adopted in the project [11]. Shi studied a large diameter $(11 \mathrm{~m})$ crossing river shield in terms of structural performance and found that, compared to " $8+1$ " scheme, " $7+1$ " partition scheme can improve the assembly rate of the lining, and the crack of segments can be reduced by incorporating PP fibers in the concrete [12]. The above studies are mainly on circular shape shield tunnel and indicate that, for tunnels with a diameter less than $6 \mathrm{~m}$, the partition number of segments is 6 and, for shield tunnel with a diameter between 8 and $11 \mathrm{~m}$, the partition number of segments is $8-10$. Wang based on rectangular shield tunnel proposed partition principles and guidelines in terms of structural force distribution, number of segments, transportation, and assembly [13]. Based on a quasi-rectangular shield tunnel, Wang et al. studied the structural behavior of the lining with 11 segments by a field test [14]. These studies got fruitful results in agreement with the lining partition scheme for circular shield tunnel with diameters around $6 \mathrm{~m}$, which was 1 wedge key segment, 2 adjacent segments, and 3 standard segments. For circular shape shield tunnels with diameter between 8 and $15 \mathrm{~m}$, the number of segments is from 8 to 10 . However, these studies of partition schemes of lining segments mainly concentrated on shield tunnels which consider the limitation of the assembly space due to the construction method. For prefabrication and assembly underpass in urban areas with cutand-cover construction method, the primary factor that should be considered in the partition scheme is not the assembly space at the site but the transportation of the segments, including the weight and dimension. The prefabricated and assembled underpass with large cross section is limited, as reported in existing literatures.

In our case, the dimension of the $22.3 \mathrm{~m} \times 8.2 \mathrm{~m}$, its cross section is much bigger than the underpass of Xianyue road undercrossing Shugang road [15]. In recent years, prefabricated subway stations have appeared in China, and many literatures focused on the performance of the station under seismic loads by model tests and numerical simulation. However, these studies rarely considered the partition schemes which are significant to the transportation, assembly, and joints performance [16-19].

Motivated by this research status, we focused on the partition schemes of a prefabrication and assembly underpass with large cross section. The case of Mozi Bridge underpass was taken as the engineering background in this paper. Based on this engineering case, a series of numerical simulations were conducted of three partition schemes. According to the numerical results and other pros and cons, an optimized partition schemes was proposed. The results of this study have been successfully used in an engineering practice.

\section{Engineering Background}

The local government planned an underpass in the center of the city of Chengdu, China, capital of Sichuan Province, to relieve traffic congestion, and its location is shown in Figure 1 . To shorten its construction period, the underpass was designed and built as a PAU.

The total length of the underpass is $980 \mathrm{~m}, 230 \mathrm{~m}$ of which is constructed in precast and assembly underpass structure, the rest of which is constructed in cast in place manner. The cross section of the underpass is $22.3 \mathrm{~m}$ in width and $8.2 \mathrm{~m}$ in height. The thicknesses of the top slab and floor slab are $1 \mathrm{~m}$, the width of the column is $0.6 \mathrm{~m}$, and the width of the lateral walls is $0.75 \mathrm{~m}$. Figure 2 shows a cross section of the underpass.

The average buried depth of the underpass is $3 \mathrm{~m}$. The prefabricated segments have a strength of C50. The waterproof capacity of the segments of the PAU is P12 (i.e., it is designed to resist a water pressure of $12 \mathrm{~m}$ ). The underpass was constructed by the cut-and-cover method, the foundation trench is supported by the retaining walls and a pile system, the floor of the trench was constructed of plain concrete C30 with a thickness of $0.5 \mathrm{~m}$, and the segments were fabricated in a factory, transported to the construction site, and assembled.

Some basic conditions must be met before designing a preliminary partition scheme. The weight of the whole ring of the tunnel is $150 \mathrm{t} / \mathrm{m}$. The current largest crane capacity is $250 \mathrm{t}$; hence, the dimension in the longitudinal direction of the tunnel was designed at $1.5 \mathrm{~m}$.

The maximum allowable height and axle of the transport rout had to be determined prior to designing the partition scheme. The height limit and the maximum allowable axle weight of the road, which the transportation of segments passed, are $5 \mathrm{~m}$ and $20 \mathrm{t}$, respectively. 




Figure 1: The location of Moziqiao PAU.

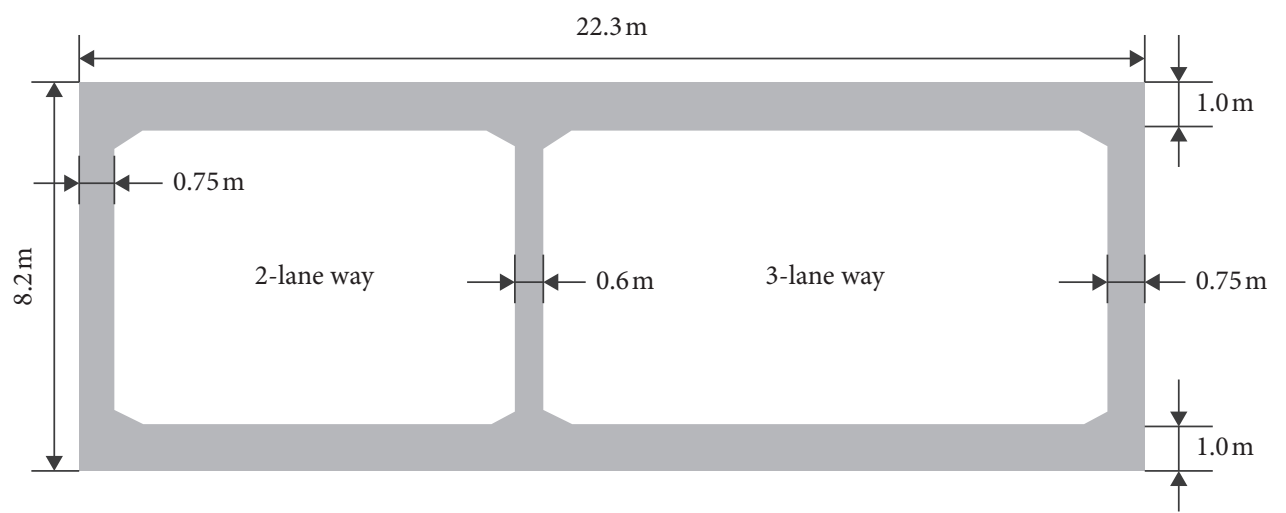

Figure 2: Cross-sectional dimensions of the underpass.

\section{Numerical Models}

The numerical simulation has two parts, that is, (1) the internal force distribution on the entire structure and (2) stress and relative deformation at the joints of the preliminary design of the division scheme.

3.1. The Distribution of the Internal Force on the Whole Structure and the Layouts of Elements in the Preliminary Design. When one considers stress, it is apparent that the joint is a weak link in the structure. The main functions of the connector are to transmit force and resist leakage. Pressure-resistant joints are easier to set up and are less important. When the joint has to transmit more complex forces, its design will be more complicated. Therefore, from the perspective of force, the joint should be set in a position with a small bending moment. According to Metro Design Code (TB 10003-2005) [20], an overall force analysis of the structure is needed in order to divide the components according to the force angle of the structure, and this analysis is done by using the structure-load model of the tunnel structure mechanics analysis in ANSYS software. The dimensions and material parameters of the model are described in the last section. The elastic resistance coefficient of the ground is $30 \mathrm{MPa} / \mathrm{m}$. The load includes the weight of the structure, the weight of the overlying soil, and the weights of the vehicles. In the structure-load model, the beam element identified as BEAM 3 usually is used to simulate the structure of the tunnel, and spring element COMBINATION 14 is used to simulate the interaction between the structure of the tunnel and the surrounding rock or soil. Figure 3 shows the distribution of the bending moment.

To obtain the optimal distribution of the stress, the joint should be placed at the position with the smallest bending moment. Hence, Figure 4(a) shows that we proposed layout 1 with the joints located at the position with 0 bending moment.

The fully prefabricated two-way rectangular underground structure was used in the Sendai subway project, and the whole structure was divided into five segments, that is, the top slab, the bottom slab, one central column, and two lateral walls [5]. This structure has a cross section that measures $11 \mathrm{~m} \times 7.5 \mathrm{~m}$. According to this partition principle, partition scheme 2 of the project was proposed as shown in Figure 4(b). 


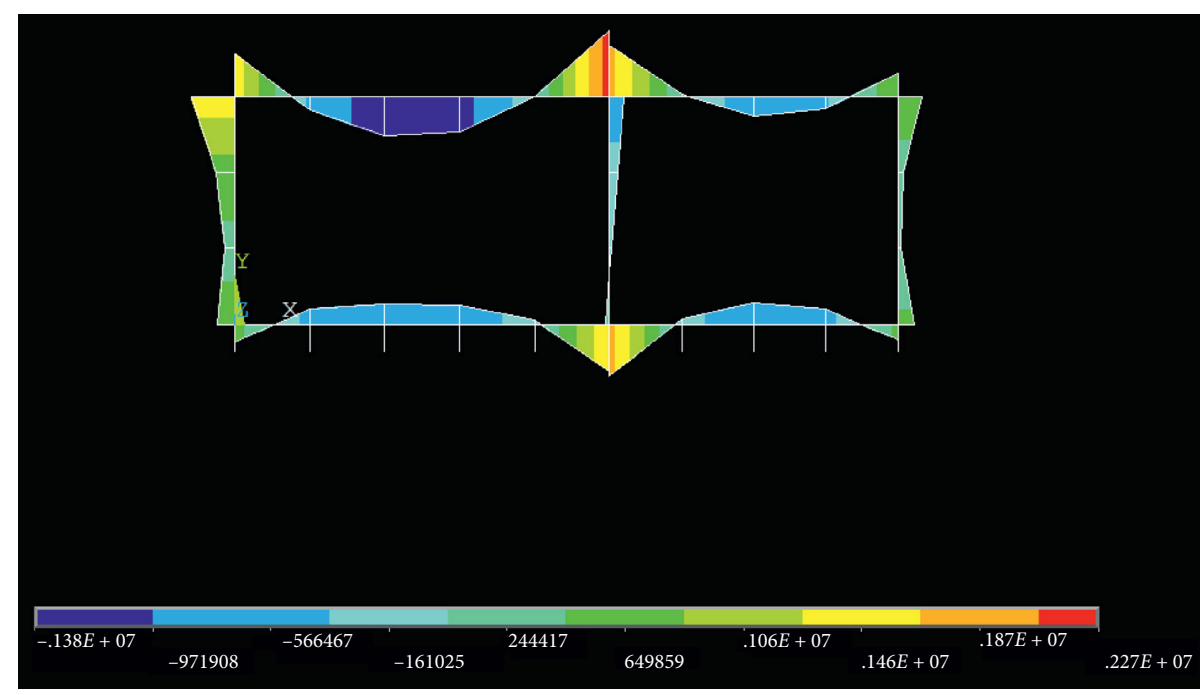

FIgURE 3: The distribution of bending moment (unit: N.m).

In 2012, a precast underpass was constructed to alleviate the traffic congestion on two main roads (express roads), that is, Shugang road and Xianyue road in Xiamen, Fujian Province [7]. Figure 4(c) shows that the cross section of the fully prefabricated tunnel is $17.3 \mathrm{~m} \times 7.2 \mathrm{~m}$.

3.2. Simulation of the Three Preliminary Division Schemes. To study the mechanical behavior of the structure and the joints of the 3-element layouts, 3 corresponding models were established in the ABAQUS code (version 2016) [21]. Figure 5 shows the dimensions of the models. Shear keys were set in the joints at the distance of $0.4 \mathrm{~m}$ apart. The dimensions of the shear box are $28 \mathrm{~cm} \times 28 \mathrm{~cm} \times 100 \mathrm{~cm}$. The thickness of the shear box is $20 \mathrm{~mm}$, and the material is Q345 steel, which has a yield strength of $345 \mathrm{MPa}$.

The dimension of the model is $43.8 \mathrm{~m} \times 10 \mathrm{~m} \times 21.7 \mathrm{~m}$ $(X \times Y \times Z)$. The bottom boundary of the model is set as rigid constraints in $X, Y$, and $Z$ directions. The front and back boundaries of the model are set as rigid in $Y$ direction. The left and right boundaries are set as rigid in $X$ and $Y$ directions. The loads conclude the weight of concrete segments, surround backfill soil, and vehicle loads (the five concentrated forces on the ground surface). The mechanical and physical parameters of the plain fill and concrete lining are shown in Tables 1 and 2, respectively. The prestress between the joints was set at $0.5 \mathrm{MPa}$, applied by the 5 pairs of concentrated forces in the models. The load of the model contained weights of the lining of the underpass and the soil, as well as the loaded vehicles on the surface. The load of every axle was set at $140 \mathrm{kN}$.

In the three models, the shear keys between the elements were set as linear elastoplastic material. The type "hard contact" (ABAQUS 2016) model was used to simulate the interaction between contact surfaces of segments. This kind of contact does not allow segments to penetrate each other at compression state. The friction coefficient was set at 0.4 , according to laboratory test. Contact surfaces between shear keys and tunnel segments were set as surface-to-surface contact type, and the friction coefficient was set at 0.2 . The "tie" mode was used to define the interaction between soil and the underpass lining. Parameters in the numerical model were the same as the real project as listed in Tables 1 and 2. In the finite element model, prestress mentioned in the last section was applied by 5 pairs of concentrated force at the top and bottom of the model for each radial joint.

\section{Optimization of Division Schemes}

The partition scheme of a PAU plays an important role during the design the stage. Thus, an optimal partition scheme was proposed based on the numerical simulation and empirical experience by comparing the number of joints, the directions of prestresses, and the stability during erection of three candidate schemes. The maximum load capacity of bridges and subgrades along the transport line was $20 \mathrm{t}$, which guaranteed that the roads and bridges were safe for the $15 \mathrm{t}$ transport vehicle. The speed of the vehicle on straight roads was about $15 \mathrm{~km} / \mathrm{h}$, and the speed when turning was about $5 \mathrm{~km} / \mathrm{h}$.

4.1. The Displacements of the Three Preliminary Schemes. From the results of computations (see Figure 6), we found that the vertical displacement of different division schemes of segments was that layout 2 has the maximum, layout 3 has the medium, and layout 1 has the minimum value. This trend was consistent with the distribution of bending moment of the entire structure. Hence, from this perspective, the optimal partition scheme of the segments is scheme 1 . The maximum vertical displacement was in layout 1 , and it was at the position of joint. But, for a practical project, there are still many factors involved in putting the chosen scheme into practice, such as the number of joints, stability during the assembly, the labor requirements, and the time required for the assembly. In the following subsection, we will compare the other factors of the three preliminary partition schemes. 


$$
\neg \quad \text { Joint }
$$

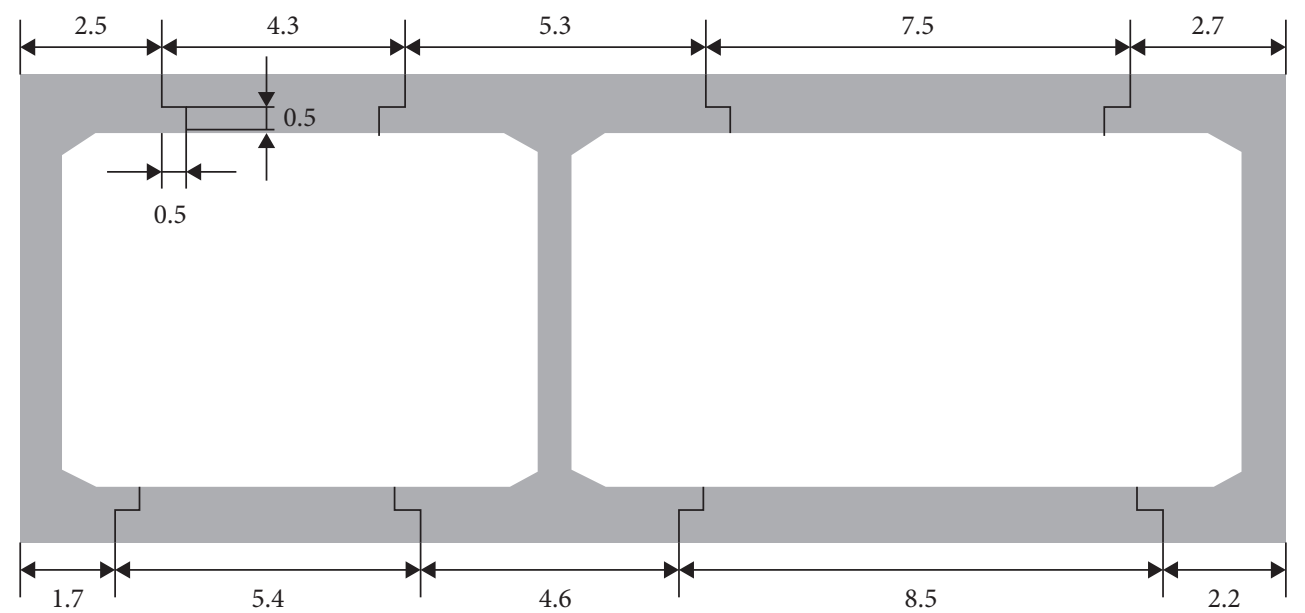

(a)

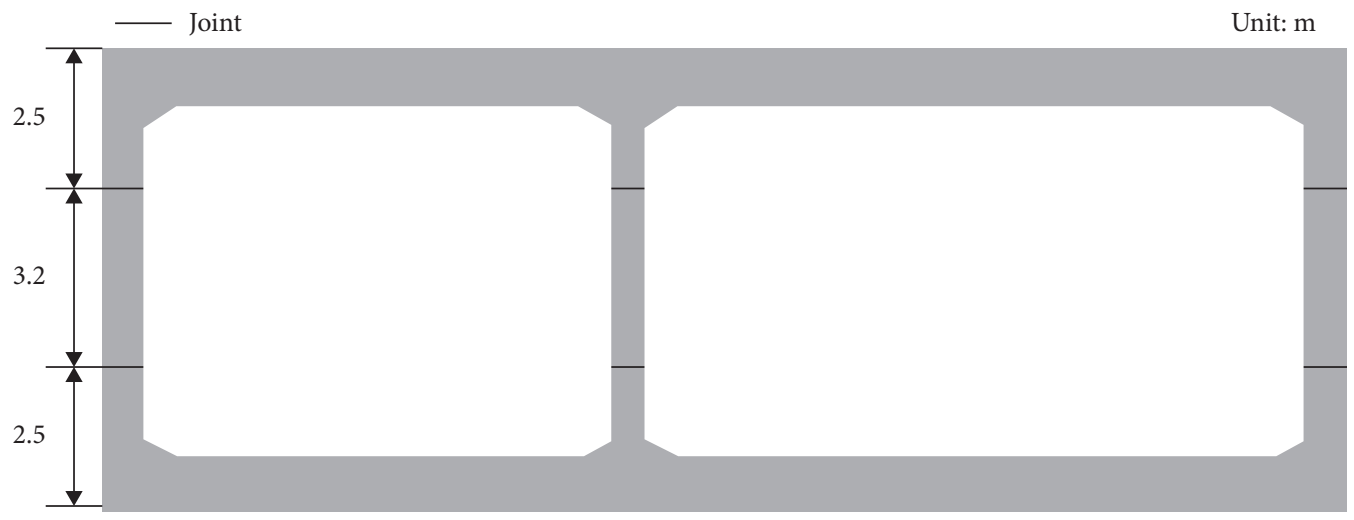

(b)

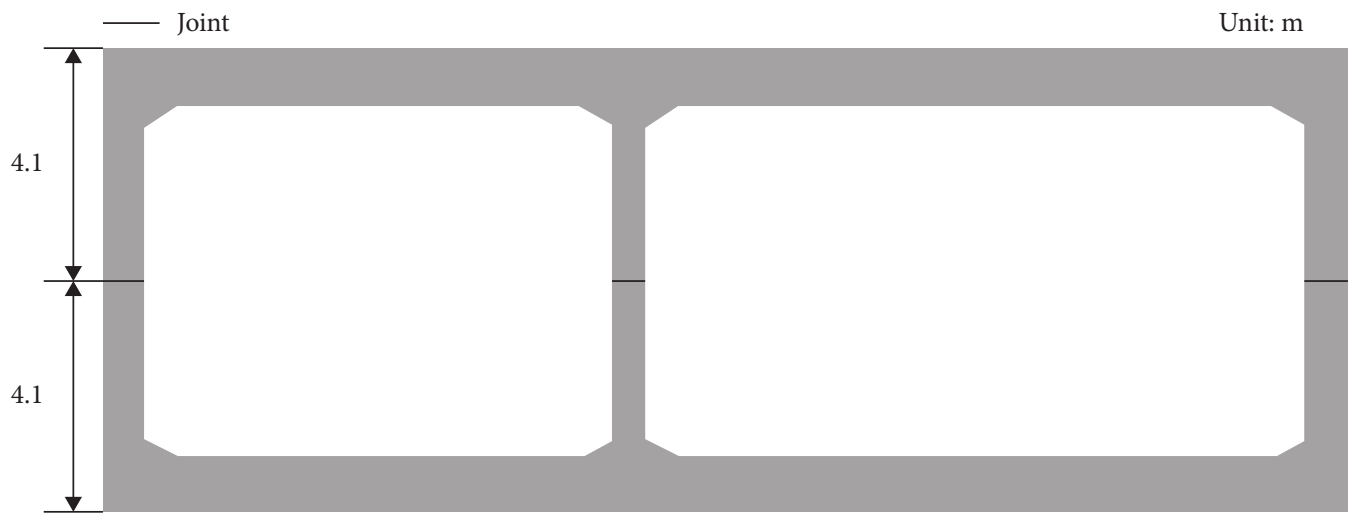

(c)

Figure 4: Preliminary division schemes: (a) scheme 1, (b) scheme 2, and (c) scheme 3.

4.2. Comparison of the Layouts of the Elements of the Underpass. In addition to vertical displacement, there are also other criteria for an optimal partition scheme, for example, the number of elements, the number of prestress directions, stability during assembly, the number of joints, and transportation. Apart from the displacement of the structure with different partition schemes. We will evaluate the advantages and disadvantages in these aspects.
The number of segments influences the number of transports, joints required, and the time required to complete the construction. Stability during construction means that the segment can maintain its stability without any additional measures, such as temporary prestress and rigid connections. Prestresses are used to ensure stability and waterproofness of the PAU. In the design stage, effort should be made to identify the direction that requires the least 


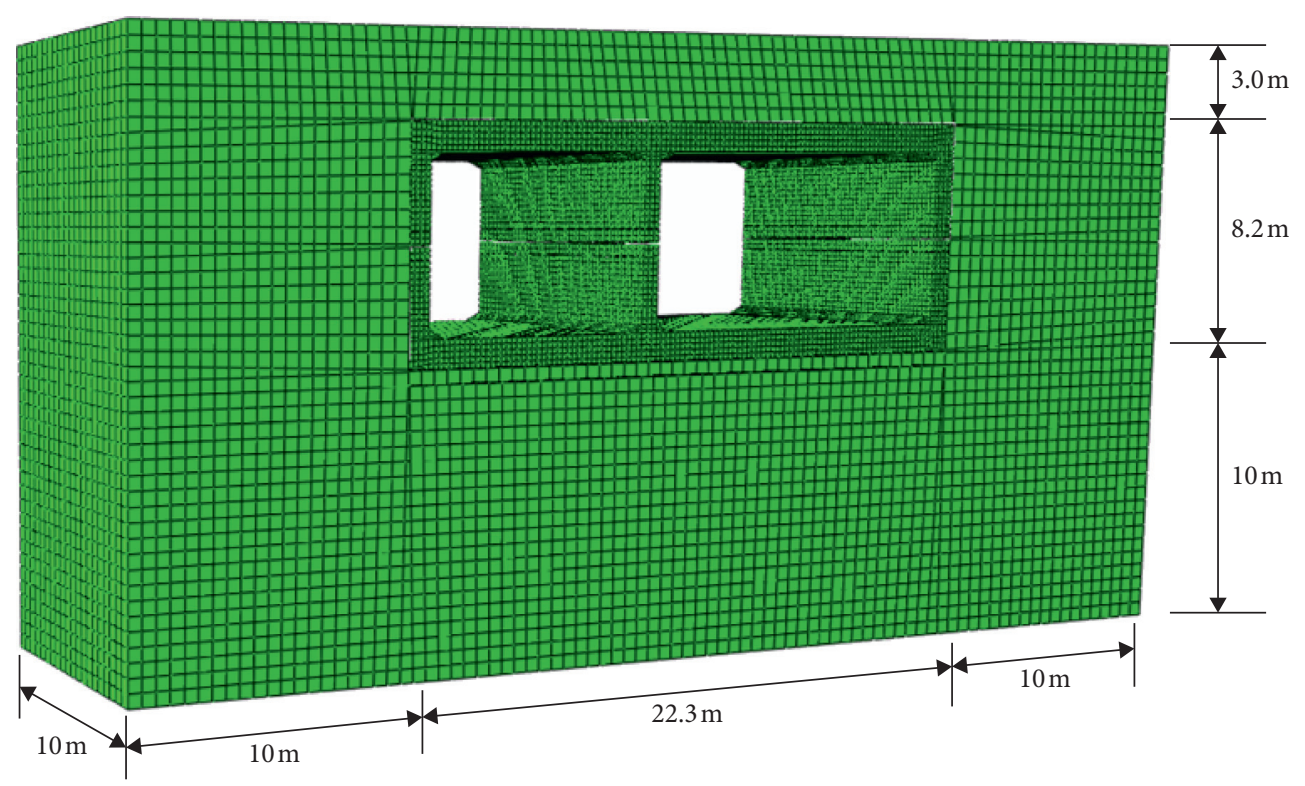

(a)

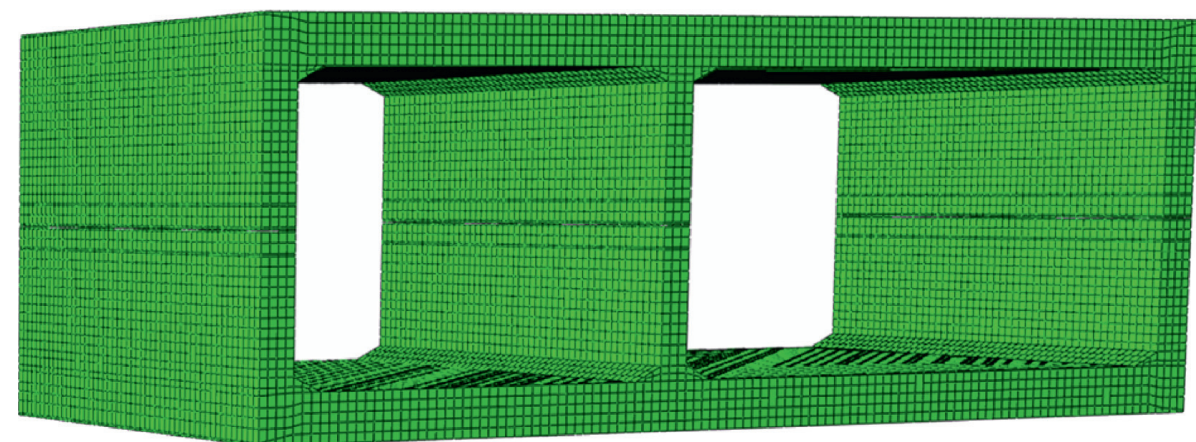

(b)

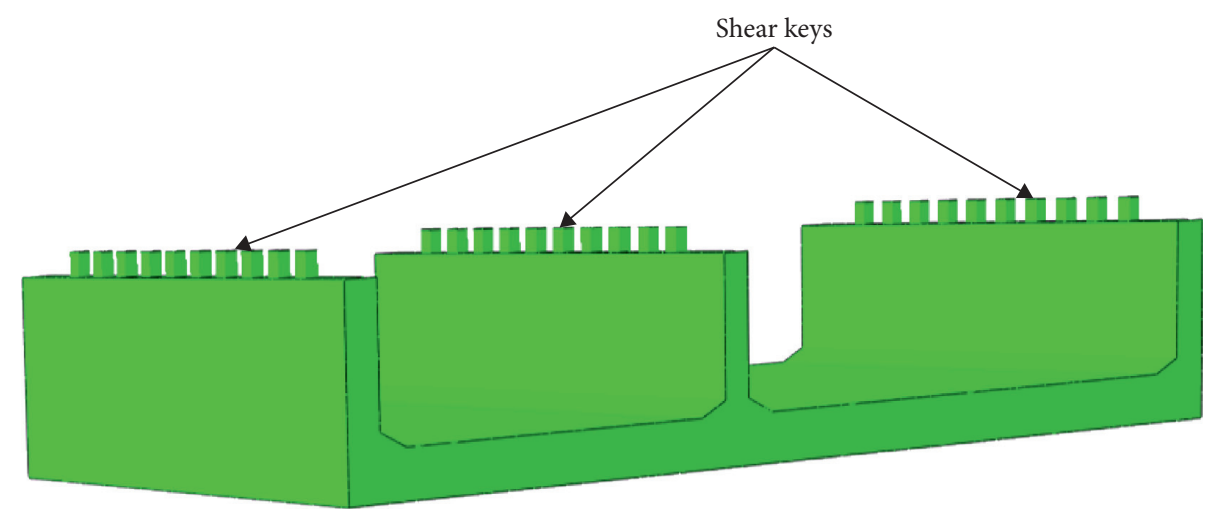

(c)

FIgURE 5: Dimensions of the simulation model: (a) whole model, (b) underpass structure, and (c) shear keys.

TABLE 1: The mechanical and physical parameters of the plain fill.

\begin{tabular}{lcccccc}
\hline $\begin{array}{l}\text { Parameters } \\
\text { Unit }\end{array}$ & $\begin{array}{c}\text { Thickness } \\
(\mathrm{m})\end{array}$ & $\begin{array}{c}\text { Density } \\
\left(\mathrm{kg} / \mathrm{m}^{3}\right)\end{array}$ & $\begin{array}{c}\text { Elastic modulus } \\
(\mathrm{MPa})\end{array}$ & $\begin{array}{c}\text { Poisson's ratio } \\
-\end{array}$ & $\begin{array}{c}\text { Friction angle } \\
\left({ }^{\circ}\right)\end{array}$ & $\begin{array}{c}\text { Cohesion } \\
(\mathrm{KPa})\end{array}$ \\
\hline Plain fill & 3 & 1910 & 57.15 & 0.32 & 18.1 \\
\hline
\end{tabular}


TABLE 2: The mechanical and physical parameters of the underpass segments.

\begin{tabular}{lccccc}
\hline Unit & $\begin{array}{c}\text { Density } \\
\left(\mathrm{kg} / \mathrm{m}^{3}\right)\end{array}$ & $\begin{array}{c}\text { Elastic modulus } \\
(\mathrm{MPa})\end{array}$ & $\begin{array}{c}\text { Poisson's ratio } \\
-\end{array}$ & $\begin{array}{c}\text { Tensile strength } \\
(\mathrm{MPa})\end{array}$ & $\begin{array}{c}\text { Compressive strength } \\
(\mathrm{MPa})\end{array}$ \\
\hline Segments & 2600 & 34500 & 0.2 & 2.64 & 52.3 \\
\hline
\end{tabular}

Vertical displacement $(\mathrm{m})$

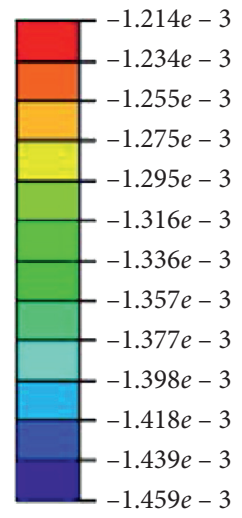

Vertical displacement $(\mathrm{m})$

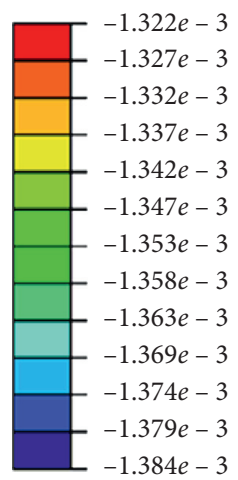

Vertical displacement $(\mathrm{m})$

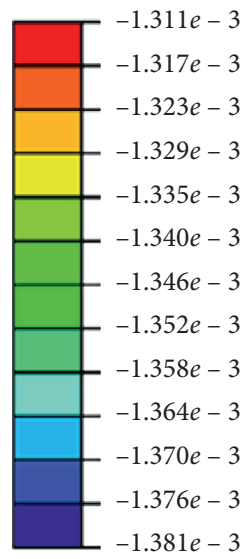

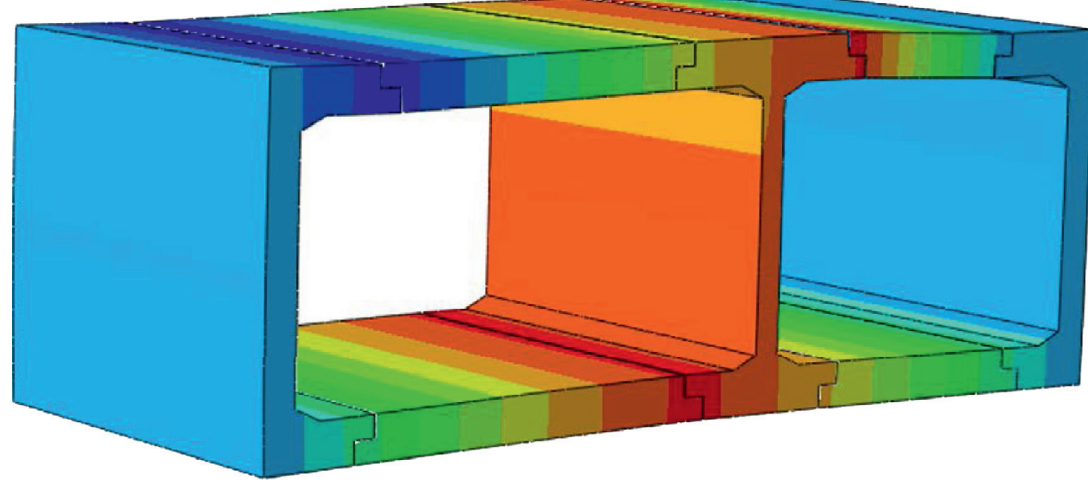

(a)

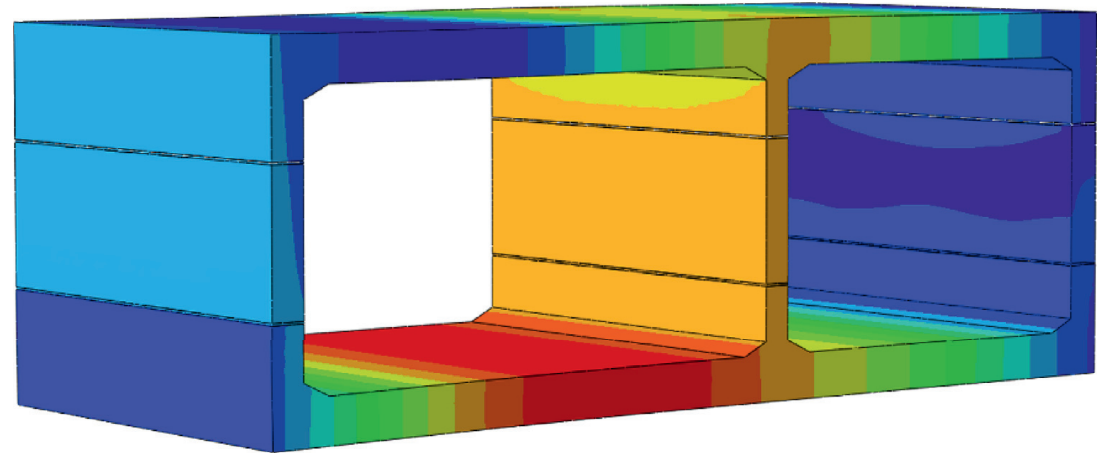

(b)

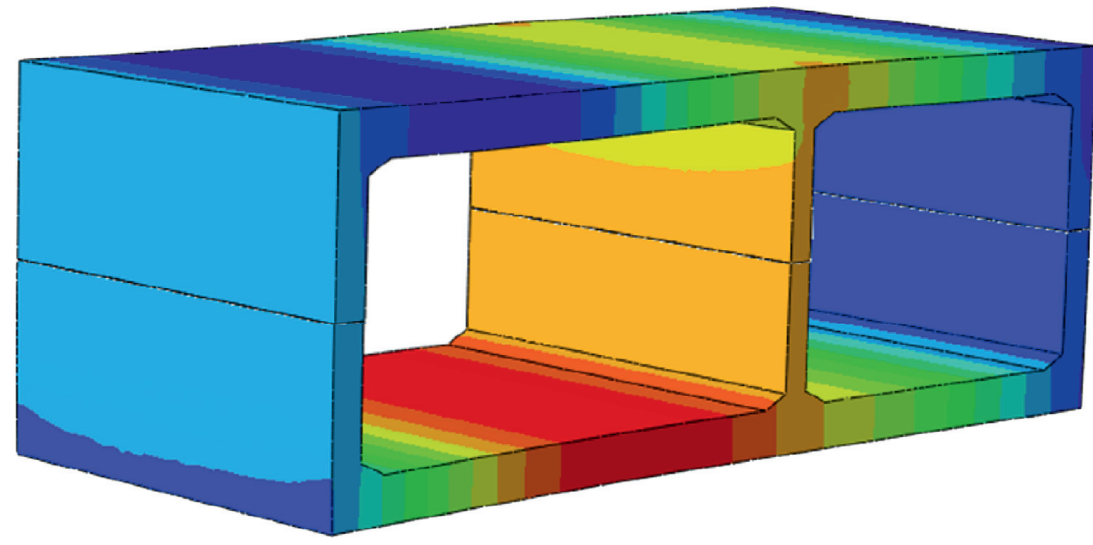

(c)

Figure 6: Vertical displacement of various schemes: (a) scheme 1, (b) scheme 2, and (c) scheme 3.

amount of prestressing. Prestressing in the longitudinal direction is necessary for all division schemes, so this topic is not discussed in this paper. In the analysis, the division of the segments which do not need additional prestress is preferable. With those criteria, the three preliminary partition schemes were compared. 
TABLE 3: The distribution of internal force at the wall center in the 3 schemes.

\begin{tabular}{lcccccccrr}
\hline \multirow{2}{*}{ Scheme } & \multicolumn{3}{c}{ Moment $(\mathrm{kN} \bullet \mathrm{m})$} & \multicolumn{3}{c}{ Shear force $(\mathrm{kN})$} & \multicolumn{3}{c}{ Axial force $(\mathrm{kN})$} \\
& RW & CW & LW & RW & CW & LW & RW & CW & LW \\
\hline 1 & 212 & -91 & 105 & 2.07 & -1.36 & -1.22 & -2930 & -3190 \\
2 & 126 & -62 & 69 & 1.96 & -1.27 & -1.16 & -2980 & -3100 & -1940 \\
3 & 298 & -106 & 126 & 2.42 & -1.57 & -1.35 & -2930 & -3120 & -2110 \\
\hline
\end{tabular}

4.2.1. Partition Scheme 1 (Seven-Segment Scheme). The weight of the largest segment per meter is $35 \mathrm{t} / \mathrm{m}$. The maximum height of the segment is $1.5 \mathrm{~m}$ (the dimension in the longitudinal direction). The most significant advantage of this scheme is that the joints at the most favorable position transfer the minimum bending moment. Both the size of the segment and its weight are the minimum values. There were 7 segments and 8 joints in this scheme. As the number of segments increases, more time is required to operate the cranes and to assemble the segments. The joints were set at the top and bottom slabs, and this required temporary prestressing in the horizontal direction to ensure stability during the assembly and a permanent prestress to ensure that the joints were waterproof.

The application of the horizontal prestress requires more space, which means that a wider foundation pit is needed, even though it is difficult to prestress the top slab.

4.2.2. Partition Scheme 2 (Five-Segment Scheme). The weight of the largest segment is $67 \mathrm{t} / \mathrm{m}$. The maximum height of the segment is 1.5 (the dimension in the longitudinal direction). There were 7 segments and 8 joints in this scheme. There are 5 segments and 6 joints in this division scheme. The position of joints in this scheme should transfer the maximum bending moment in the three schemes.

4.2.3. Partition Scheme 3 (Two-Segment Scheme). The weight of the largest segment in this scheme is $75 \mathrm{t} / \mathrm{m}$. The maximum height of the segment is $1.5 \mathrm{~m}$ (the dimension in the longitudinal direction). There are 2 segments and 3 joints in this scheme. The prestress should be applied in the vertical direction. The columns are not stable during the assembly and additional measures are required for safety purpose. Wang et al. [22] reported that the location of joints cannot affect the distribution of the bending moments of the whole structure significantly.

The comprehensive comparison of the candidate schemes is significant to optimize partition scheme. The internal forces of the three schemes at the center of the three walls are listed in Table 3. The internal forces are nearly the same for the three schemes in addition to the fact that scheme 3 is the biggest one. This is mainly due to the fact that the little deformation occurs at the joints. The maximum bending moment of all the three schemes is at the right side of the central column. This is mainly induced by the asymmetrical property of the structure. The three candidate schemes have no obvious difference in terms of distribution of internal force for the prestress and the shear boxes in the joints. For the partition scheme, the internal forces around the joints are very important during the optimal structural partition. However, in a real project, there are other factors such as segment weight, the maximum dimension, assembly time, the requirement size of the foundation pit, and the numbers of the prestress directions and joints. The comparison of these factors is given in Table 4 . Scheme 1 has the minimum segment weight and span but the most segments and joints. Therefore, this scheme needs the longest assembly period, and for the horizontal joints the additional prestress in this direction is needed, which requires a wider size of the foundation pit and longer build time. In schemes 2 and 3 , the only difference in partition is that in scheme 2 all the walls are cut into 3 parts, while in scheme 3 the structure is cut into two symmetry segments. The additional rectangular segments need much more time in assembling for their poor stability, which costs longer assembled time. In all candidate schemes, the size and weight of the biggest segment can satisfy the transportation and lifting. Scheme 3 has the fastest build speed and least prestress directions. For the comprehensive comparison and the engineering desire of fast construction, scheme 3 is the best partition scheme.

4.3. Sensitivity Analysis of the Three Schemes. As described in Section 3, the weights and dimensions of the three partition schemes can satisfy the requirement of current transportation and crane ability. Hence, the size and weight are not considered in the sensitive analysis. A radar chart was used to analyze the sensitivity of the internal force at joints, the number of joints, the prestress directions, and the stability during assembly.

In the radar chart, the colored points indicate the influence of the criteria. The influence of each criterion increasing means that the position of the point locates outward the ring and vice versa. The score of each criterion ranges from 1 to 3 . The lines connecting the points indicate the pros and cons of the schemes. In Figure 7, scheme 3 covers the largest area, which means that this is the best partition scheme. Apart from the aforementioned criteria, in scheme 3 , the dimensions of the two segments are the same, and they can be prefabricated by the same mold.

\section{Construction of the Fully Prefabricated and Assembled Underpass}

After the design is completed, support of the foundation pit was provided, and the segment mold was fabricated. Also, a retaining wall was constructed before the trench was excavated. Afterwards, the complete foundation of the PAU was poured, and three tracks were assembled. Figures 8(a)8 (c) show the prefabrication of the segments, demolding, 
TABLE 4: The comprehension comparison of the three schemes.

\begin{tabular}{lccccc}
\hline Scheme & Weight & Size & Span & No. of joints & - \\
Unit & $\mathrm{t}$ & $\mathrm{m}$ & $\mathrm{m}$ & $\begin{array}{c}\text { Build speed } \\
\text { Ring/day }\end{array}$ \\
\hline 1 & 35 & 2.5 & 8.5 & 8 & 0.4 \\
2 & 67 & 2.5 & 22.3 & 6 & 0.8 \\
3 & 75 & 4.1 & 22.3 & 3 & 1.5 \\
\hline
\end{tabular}

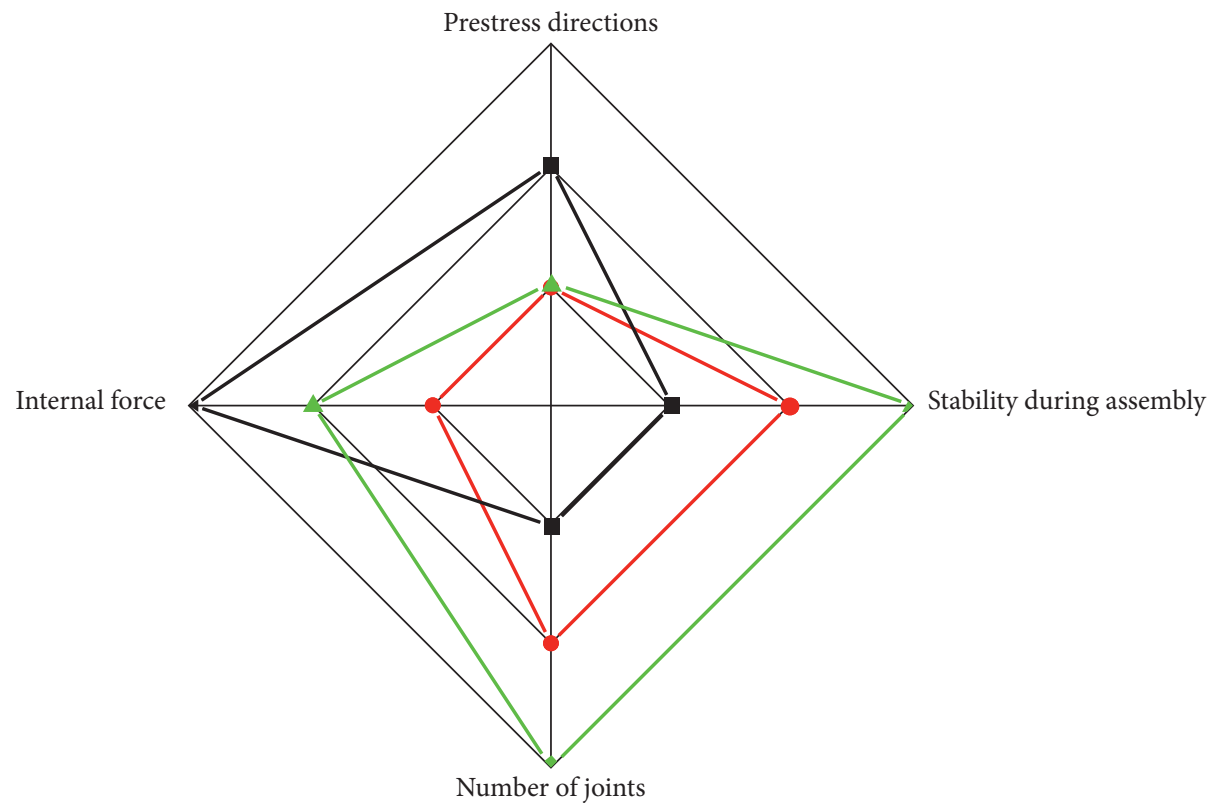

-- Scheme 1

-- - Scheme 2

- - Scheme 3

Figure 7: Comparison of the three schemes.

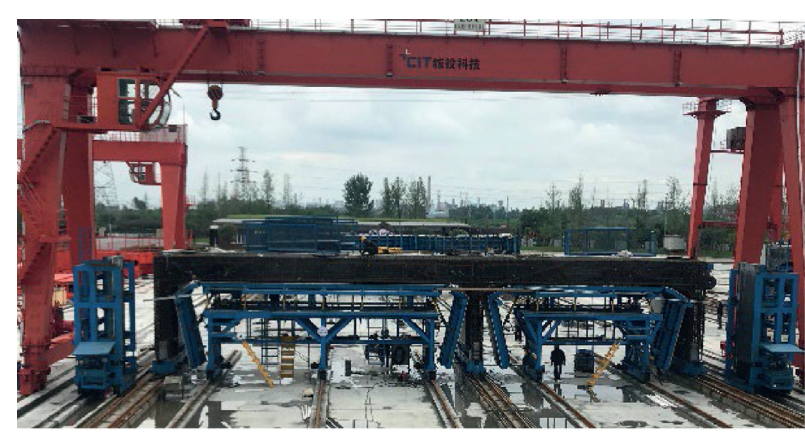

(a)

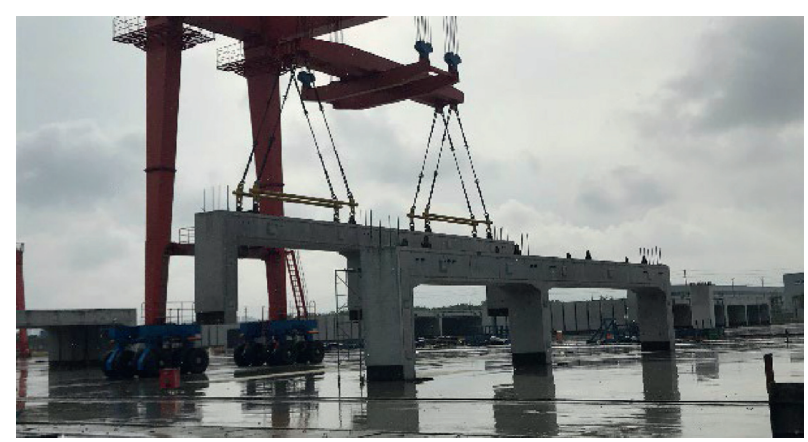

(c)

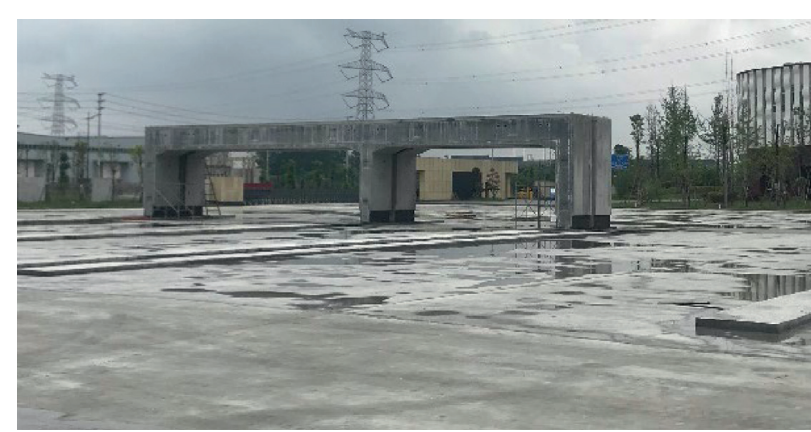

(b)

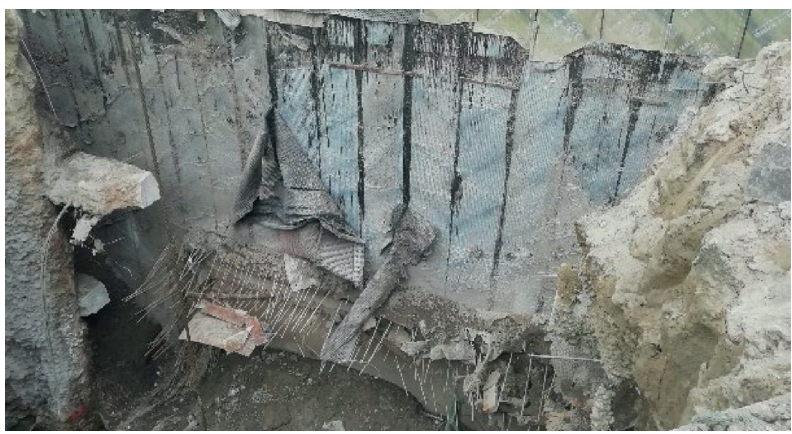

(d)

FIGURE 8: Prefabrication of the segments and construction of the trench: (a) segments mold, (b) prefabricated segments, (c) segment layout, and (d) trench excavation and support. 


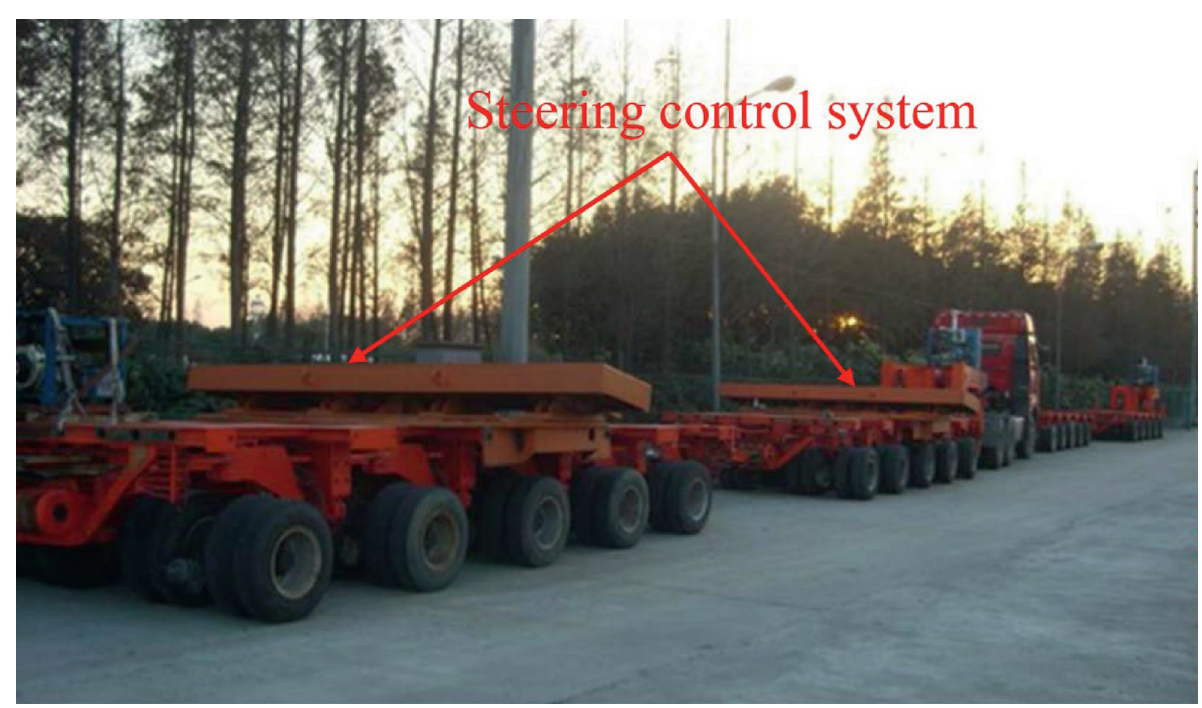

(a)

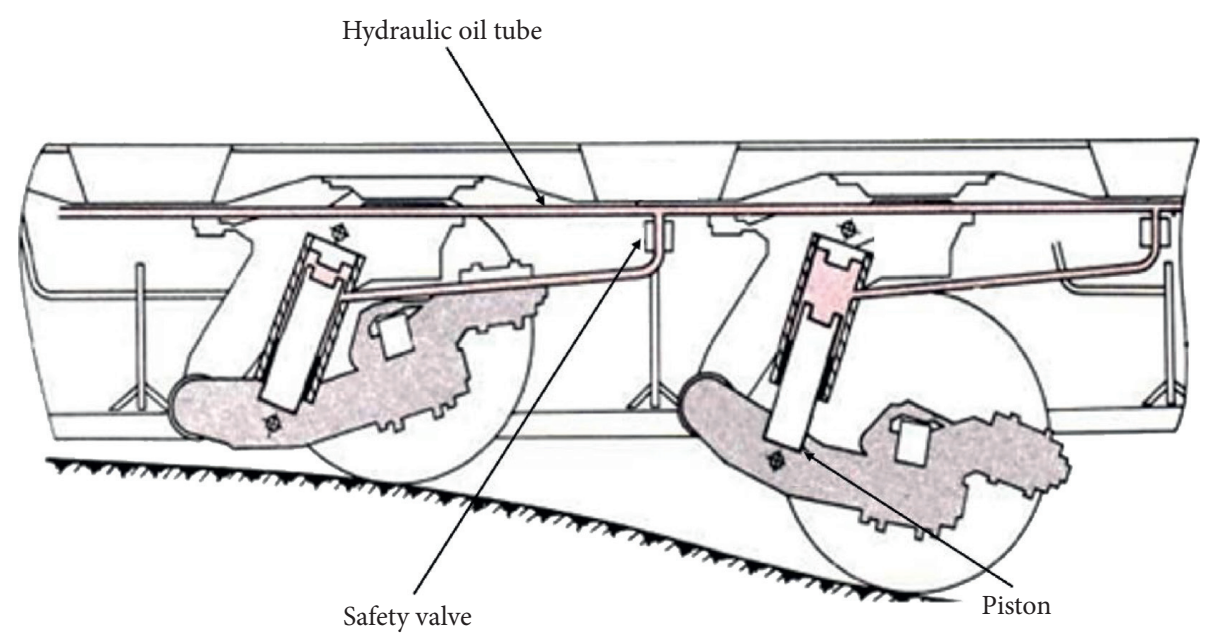

(b)

FIgURE 9: Special design of transportation: (a) the steering system; (b) automatic vertical balancing device.

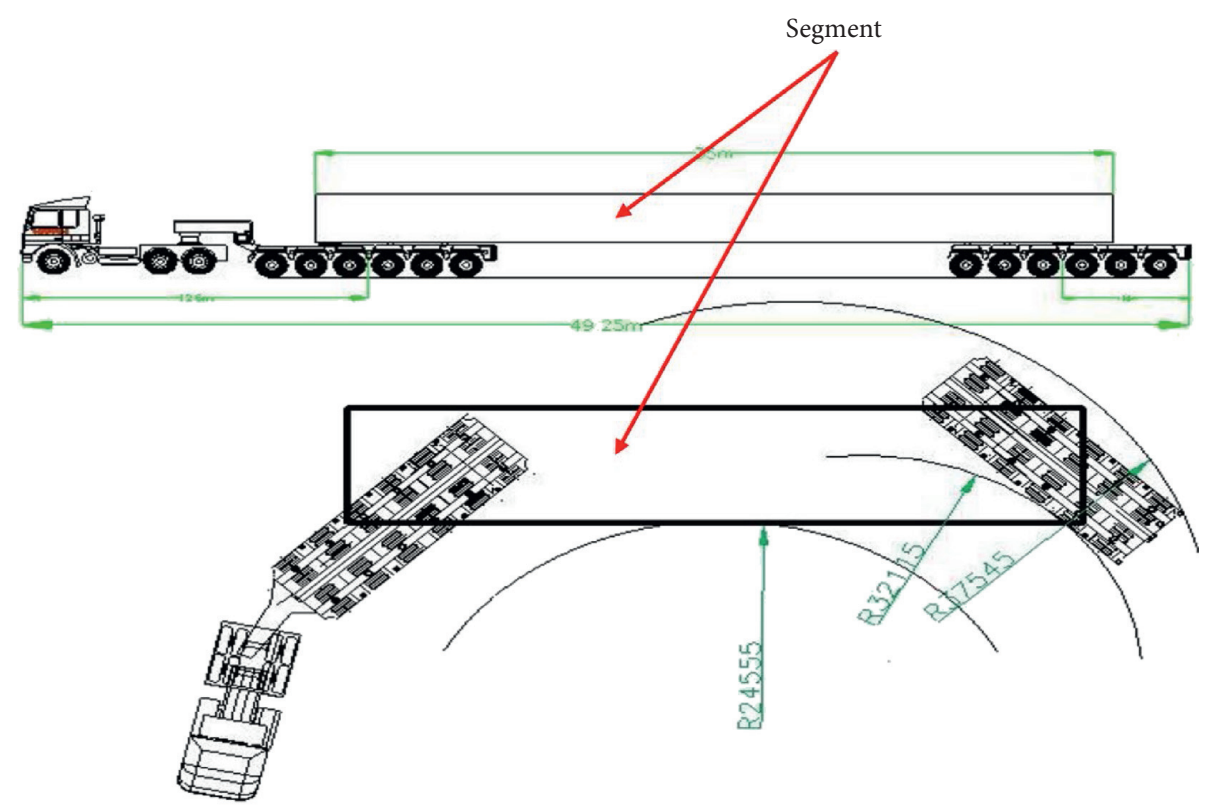

FIGURE 10: Working principles diagram of the steering system. 
and the layout, respectively. The excavation of the trench was shown in Figure 8(d).

As shown in Figures 9 and 10, the steering system is a pair of hydraulic flat turntable mechanisms. Through the adjustment of the steering hydraulic system and the reasonable arrangement of the connecting rods, the vehicle can achieve splay steering, thereby minimizing the turning radius. To ensure that the segments maintain a uniform height, a hydraulic cylinder is set to make the frame free lift, as shown in Figure 9(b). All suspension hydraulic cylinders are connected unilaterally through the hydraulic oil tubes.

\section{Conclusions}

This paper investigated the partition schemes of a prefabricated and assembled underpass (PAU) with large cross section. Three preliminary schemes were proposed by the internal force distribution and completed similar projects. The size and weight of the maximum segments were satisfied with the transportation and hoisting requirement among all the three schemes. The three schemes were compared in terms of internal force distribution with the connection of the joints, number of joints, number of prestress directions, and construction efficiency. Results show that the partition scheme of two segments is the optimized one, and the internal forces are nearly the same as the seven-segment scheme, but, with the shortest construction time, five-segment scheme needs more assembling time, and the three columns have poorer stability during erection. For a PAU, the construction speed is the primary factor to be considered, provided that other mechanical requirements are met. In addition, the construction procedure was also introduced briefly.

\section{Data Availability}

The data used to support the findings of this study are available from the corresponding author upon request.

\section{Conflicts of Interest}

The authors declare that there are no conflicts of interest regarding the publication of this paper.

\section{Acknowledgments}

This work was supported by the National Natural Science Foundation of China (Grant no. 51978582).

\section{References}

[1] B. G. A. Van Casteren, "Feasibility of prefabricated concrete elements for underpasses (watertight connection \& structural safety)," M.S.C. E. thesis, Delft University of Technology, Rotterdam, Netherlands, 2015.

[2] X. R. Yang, M. L. Huang, and F. Lin, "Research strategies on new prefabricated technology for underground metro stations," Urban Rail Transit, vol. 5, pp. 1-10, 2019, in Chinese.

[3] D. C. WangG. F. Wang et al., "The application and prospect analysis of prefabricated construction in underground engineering," China Scie 'nce Paper, vol. 13, pp. 115-120, 2018, in Chinese.
[4] Y. B. Lai, M. S. Wang, X. H. You et al., "Overview and outlook for protection and prefabrication techniques of tunnel and underground projects," Building Technique Development, vol. 42 , pp. $24-28,2015$, in Chinese.

[5] H. M. Liu, "Study on mechanical properties of assembled lining in open-cut section of underground railway," Master's thesis, Southwest Jiaotong University, Chengdu, China, 2003.

[6] N. S. Rasmussen, "Concrete immersed tunnels - forty years of experience," Tunnelling and Underground Space Technology, vol. 12, no. 1, pp. 33-46, 1997.

[7] F. Li, "Research on key technologies of Shugang road undercrossing Xianyue road," Fujian Building Materials, vol. 155, pp. 51-53, 2014, in Chinese.

[8] L. H. Pei, "Shield tunnel segment structure design research," Railway Standard Design, vol. 12, pp. 87-91, 2009, in Chinese.

[9] Z. Q. Lu, "Lining segment design proposal of Wuhan Yangtze River shield tunnel," Underground Engineering and Tunnels, vol. 2, pp. 23-25, 2006, in Chinese.

[10] Q. X. Yan, C. Y. Wang, D. J. Zheng et al., "Conformation design and statistical analysis of large underwater shield tunnel," Railway Standard Design, vol. 2, pp. 99-104, 2016, in Chinese.

[11] W. T. Chen, Z. Y. Jiang, Y. C. Dong et al., "Discussion on the partition design of large diameter double-shield TBM tunnel segments," Journal of Railway Science and Engineering, vol. 15, no. 1, pp. 170-177, 2018, in Chinese.

[12] Z. Shi, "Structural design of large diameter underwater shield power tunnel," Science and Technology Innovation, vol. 56, no. 4, pp. 115-117, 2019, in Chinese.

[13] Q. S. Wang, "Case study based analysis of segment division principles of rectangular shield tunnels," Modern Tunnelling Technology, vol. 56, no. 4, pp. 23-29, 2019, in Chinese.

[14] D. F. Wang, W. X. Zhang, Z. B. Dong et al., "Experimental field study on the structural behaviors of the linings of quasirectangular shield tunnels," Modern Tunnelling Technology, vol. 53, no. 6, pp. 174-181, 2016, in Chinese.

[15] Z. Jin, T. Qi, X. Liang et al., "Radial joints behavior of a precast asymmetric underpass induced by long-term loads of ground vehicles," Shock and Vibration, vol. 2020, Article ID 5952796, 11 pages, 2020.

[16] P. Ding, L. Tao, X. Yang, J. Zhao, and C. Shi, "Three-dimensional dynamic response analysis of a single-ring structure in a prefabricated subway station," Sustainable Cities and Society, vol. 45, pp. 271-286, 2019.

[17] X. Yang and F. Lin, "Prefabrication technology for underground metro station structure," Tunnelling and Underground Space Technology, vol. 108, Article ID 103717, 2021.

[18] X. Yang, Z. Shi, F. Lin et al., "Influence of geometrical parameters on performance of grouted mortise and tenon joints for application in prefabricated underground structures," Advances in Civil Engineering, vol. 2019, Article ID 3747982, 14 pages, 2019.

[19] L. Tao, P. Ding, C. Shi, X. Wu, S. Wu, and S. Li, "Shaking table test on seismic response characteristics of prefabricated subway station structure," Tunnelling and Underground Space Technology, vol. 91, Article ID 102994, 2019.

[20] The people's Republic of China Code, Code for Metro Design (TB 10003-2005), China Architecture and Building Press, Beijing, China, 2005.

[21] ABAQUS Inc., ABAQUS User's Manual-Version 2016, ABAQUS Inc., Johnston, RI, USA, 2016.

[22] M. N. Wang, Z. Y. Li, and B. S. Guan, "Study on prefab concrete lining technology for open trench subway tunnels," Journal of the China Railway Society, vol. 26, no. 3, pp. 88-91, 2004, in Chinese. 